J. Management and Humanity Research

Vol. 4, 2020, 9-22

ISSN: 2582-7766 (online)

Published on 25 January 2021

www.researchmathsci.org

DOI: http://dx.doi.org/10.22457/jmhr.v04a04202

Journal of

Management and

Humanity Research

\title{
Construction and Model Analysis of the Bidirectional E-Business Credit Evaluation System
}

\author{
Qin-qin Fu ${ }^{1}$ and Pacheco Reyes Constantino Cristhian ${ }^{2}$
}

${ }^{1}$ School of Management, Guangzhou University, Guangzhou-510006, China.

Email: 451417524@qq.com

${ }^{2}$ School of Management, Instituto Politécnico Nacional

Mexico City 50300, Mexico. Email:Cristhian1012@gmail.com

Received 23 November 2020; accepted 12 January 2021

Abstract. This paper discusses the credit evaluation problem in E-Business. We propose a new method called two-way credit evaluation after analyzing the defect of present EBusiness credit evaluation method, which concentrates on unilateral evaluation. The new method simultaneously takes both the buyer and the seller into consideration to analyze, which is beneficial to ensure the credit evaluations' consistency, authority and compatibility. This paper explains the frame structure of bidirectional E-Business credit evaluation model, the operation mode and the implementation method. Further, the paper simulates the implementation of bidirectional E-Business credit evaluation model by applying the analytic hierarchy process (AHP) model.

Keywords: E-Business; Credit; Analytic Hierarchy Process

\section{Introduction}

The e-commerce credit system (Wei Mingxia et al., 2007) refers to the collection, sorting, and verification of the credit status of members involved in e-commerce activities in the process of e-commerce activities, as well as the supervision and management established by national, local or industry management departments The sum of a series of mechanisms and codes of conduct for the normative development of credit activities of relevant members. Compared with the "one-handed payment, one-handed delivery" model in the context of the real economy, in the context of e-commerce, since logistics and capital flows are not synchronized, the possibility of default is greatly increased, and the impact of credit on economic transactions is particularly prominent. Credit is the foundation of a market economy. Lack of credit will increase transaction costs, even lead 


\section{Qin-qin Fu and Pacheco Reyes Constantino Cristhian}

to the interruption of the transaction chain, affect economic development, and hinder social progress.

With the vigorous development of China's economy, the e-commerce industry has also quietly emerged across the country, impacting the real economy with a swift and violent momentum, and also driving the development of the entire economy. The economic chain it forms runs through all aspects of society, and gradually affects the value creation methods of society and people's living habits. In addition to the advantages of economy and convenience, e-commerce has also presented many contradictions in the development process: on the one hand, merchants have repeatedly appeared such as false transactions, counterfeiting, contract fraud, online auction bids, malicious breach of contracts, and information stolen. Modifications and other acts that infringe the legitimate rights and interests of consumers; on the other hand, it is not uncommon for consumers to fabricate false credit evaluation information and intentionally return goods in ecommerce transactions. These phenomena have attracted great attention from consumers, merchants, e-commerce platform operators, relevant regulatory agencies, researchers and other groups, and have questioned the validity of the current e-commerce credit evaluation model. In recent years, vicious incidents such as "shouyimen", "credit rating scrutiny", and "professional critics" have put e-commerce in the heat.

Aiming at the question of how to construct an effective e-commerce credit system, this article will conduct the following research: First, introduce the current credit evaluation model in the e-commerce environment, and analyze its limitations; then, propose the two-way electronic The business credit evaluation model summarizes the construction principles of the model, and specifically explains its framework structure, operation mode and implementation methods; secondly, the two-way e-commerce credit system is numerically simulated using the analytic hierarchy model, and the two-way credit results are explained based on the simulated data; Finally, summarize the research conclusions, and look forward to the future improvement direction of e-commerce credit evaluation.

\section{Current research status on e-commerce credit issues}

\subsection{Summary of related research}

E-commerce credit systems were introduced earlier in foreign countries. Martin (1977) and Frank (1983) used Logistic technology to select financial ratios reflecting the company's solvency, profitability, management ability, and liquidity as preselected indicators, and used historical data to compare The pre-selected indicators are tested for significance and multicollinearity to calculate the probability of enterprise default and then judge the creditworthiness of the enterprise. Tran and Cohen conducted research on e-commerce security and commercial fraud, combined with the characteristics of 
Construction and Model Analysis of the Bidirectional E-Business Credit Evaluation System

reputation mechanism setting, and proposed a systemic risk prevention mechanism to reduce the credit risk in the process of e-commerce credit transactions. Chenga and Chiangb proposed to apply the data envelopment analysis (DEA) method to establish a credit evaluation model, combined with decision tree, neural network and other methods, they established a scoring system containing more than ten indicators, based on the information obtained from current observations, Calculate the credit score of the evaluated object, and then evaluate the credit level of the enterprise. Domestic research on the establishment of an e-commerce credit system, since the "Guiding Opinions on the Establishment of a Pilot Credit Guarantee System for Small and Medium-sized Enterprises" was issued in June 1999, has also achieved rich results. For example, Ma Qingguo (2004) put forward the concept of "incomplete e-commerce" from the perspective of network security through an empirical analysis of e-commerce problems in Zhejiang Province, and pointed out that this e-commerce model needs to solve the problem of information flow and improve E-commerce system and perfect e-commerce legal system. Peng Hui and Wu Hong (2011) comprehensively discussed the credit influencing factors and product characteristics of the e-commerce market, and proposed that due to the differences in the integrity environment in the product sub-markets, a differentiated credit rating evaluation system should be established in the e-commerce transaction platform to solve the problem. Differences in results caused by ignoring differences in the transaction subject itself. Jiang Minghui et al. (2004) used the personal credit evaluation model of k-nearest neighbor discriminant analysis method, used a small sample set of data to apply the model, determined the corresponding evaluation index system, and integrated the personal credit in the process of participating in the market economy. Evaluation to determine the individual's ability to obtain a certain service and its credibility.

\subsection{Research review}

Looking at the existing research, it can be found that the main mode of studying ecommerce credit systems at home and abroad is the unilateral credit evaluation method, that is, only a certain type of e-commerce transaction subject is selected as the evaluation object, from the aspects of evaluation standards, evaluation methods, and data sources Through the establishment of a quantitative model, its credit status is evaluated, and ecommerce credit users are persuaded to approve the evaluation results of the credit mechanism. This research model can be summarized in Table 1. However, this article believes that this credit evaluation mechanism that considers the evaluation subject and object from a single direction is too much to stay in the evaluation of the unilateral credit evaluation objects of enterprises or individuals, and separate the credit objects from time 


\section{Qin-qin Fu and Pacheco Reyes Constantino Cristhian}

and space. Independent and one-way credit evaluation, thus failing to consider all parties involved in e-commerce transactions, and unable to objectively and fairly evaluate the credit of both buyers and sellers. However, the e-commerce system is a complex system. To make the entire industrial chain develop harmoniously, a single-direction e-commerce credit assessment can no longer meet the participants' needs for credit symmetry and fairness.

The key to solving the problem lies in how to break this one-way credit evaluation model. This article attempts to establish a two-way e-commerce credit system from the perspective of all participants in e-commerce transactions, so that while online merchants can obtain fair treatment from consumers It can also be treated fairly by online merchants. Both parties to the transaction can obtain symmetrical information and build a platform for fair transactions. This new two-way e-commerce credit evaluation system can improve the unfairness of the traditional one-way credit evaluation model.

Table 1: Current research models of e-commerce credit evaluation issues

\begin{tabular}{c|l|l|l}
\hline $\begin{array}{c}\text { Independent } \\
\text { credit } \\
\text { Evaluation } \\
\text { object }\end{array}$ & \multicolumn{1}{|c|}{$\begin{array}{c}\text { Credit data } \\
\text { source }\end{array}$} & Analytical method & Typical conclusion \\
\hline $\begin{array}{c}\text { Enterprise } \\
\text { (merchant) }\end{array}$ & $\begin{array}{l}\text { Financial ratios, } \\
\text { transaction } \\
\text { records, etc. }\end{array}$ & $\begin{array}{l}\text { Decision tree, data } \\
\text { envelopment analysis, fuzzy } \\
\text { comprehensive evaluation, } \\
\text { etc. }\end{array}$ & $\begin{array}{l}\text { Merchant credit } \\
\text { rating: excellent, } \\
\text { good, medium, poor }\end{array}$ \\
\hline $\begin{array}{l}\text { Individual } \\
\text { (consumer) }\end{array}$ & $\begin{array}{l}\text { Economic } \\
\text { status, } \\
\text { consumption } \\
\text { habits, etc. }\end{array}$ & $\begin{array}{l}\text { k-nearest neighbor } \\
\text { discriminant analysis } \\
\text { method, differential credit } \\
\text { rating evaluation system, } \\
\text { etc. }\end{array}$ & $\begin{array}{l}\text { Consumer credit: } \\
\text { high, low }\end{array}$ \\
\hline
\end{tabular}

\section{Two-way e-commerce credit system}

\subsection{Basic architecture}

The so-called two-way, mainly for the evaluation object, that is, the evaluation object of credit is not only the merchant or the consumer side, but includes both parties at the same time, so as to ensure that the key parties in the transaction process can participate in the credit evaluation and evaluation in a fair, symmetrical and equal manner. Use credit assessment results. The essence of the two-way e-commerce credit evaluation system is to establish a network structure that takes the two-way credit evaluation center as the connection point, takes the merchants and consumers as the credit evaluation objects, and 
Construction and Model Analysis of the Bidirectional E-Business Credit Evaluation System

obtains credit information from banks, websites and other institutions, as shown in Figure 1. The system connects all participants in the e-commerce transaction process, organizes the collected various aspects of information and data, comprehensively considers, and according to certain weights, finally forms an intuitive, fair and comparable credit evaluation result. The core of the model is the two-way credit evaluation center, which is the key to connecting the entire network model. It coordinates the relationship between the two parties in the transaction and acts as a balance in the evaluation process. The credit rating center needs to collect credit information from multiple parties involved in the transaction process as a basis for credit evaluation of merchants and consumers. The relevant entities mainly include third-party payment platforms, banks, etc. Among them, the third-party payment platform is a third-party service-type intermediary agency, which mainly provides basic e-commerce support and application support services for enterprises, and does not directly engage in specific e-commerce activities. The intervention of a third-party payment gateway can avoid direct economic transactions between the parties to the transaction and is an important guarantee for the smooth completion of the transaction under the environment of lack of integrity. Banks are the direct controllers of funds in transactions, connecting consumers, payment gateways, and merchants to form a capital transaction chain. As a financial institution, the financial information it provides plays an important role in the credit assessment of merchants and consumers. Based on the collected various aspects of information, the Credit Rating Center conducts a comprehensive assessment of the credit of merchants and consumers, and gives the results. While publishing on the information publishing platform, the evaluation results are fed back to relevant merchants and consumers, and participate Both parties to the transaction determine whether to conduct a transaction based on the evaluation result. 


\section{Qin-qin Fu and Pacheco Reyes Constantino Cristhian}

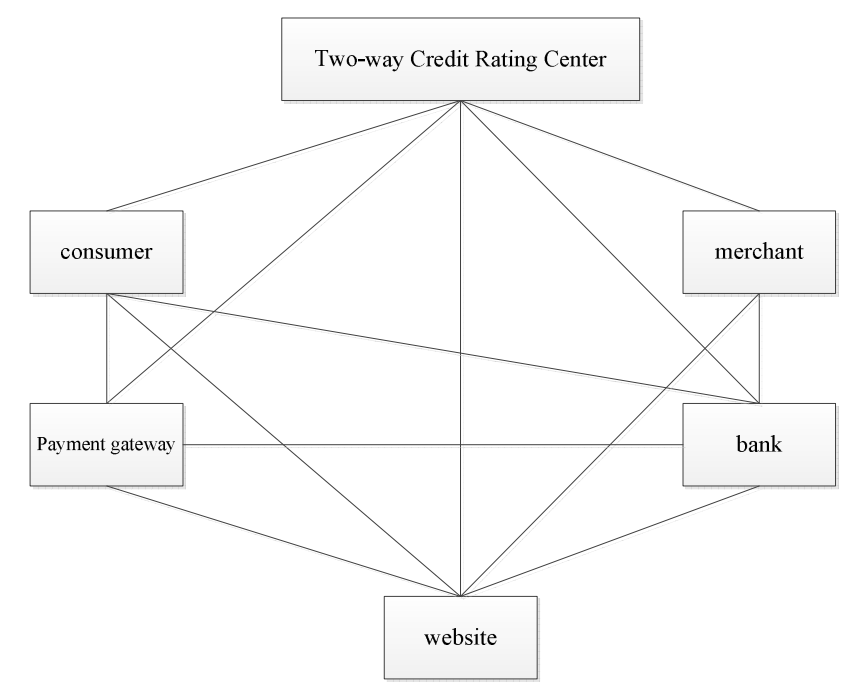

Figure 1:Network diagram of two-way e-commerce participants

\subsection{Operating mode}

The operating process of the two-way e-commerce credit system constructed in this article can be summarized as the conceptual model shown in Figure 2. The main operating steps and processes are introduced in the order of occurrence below.

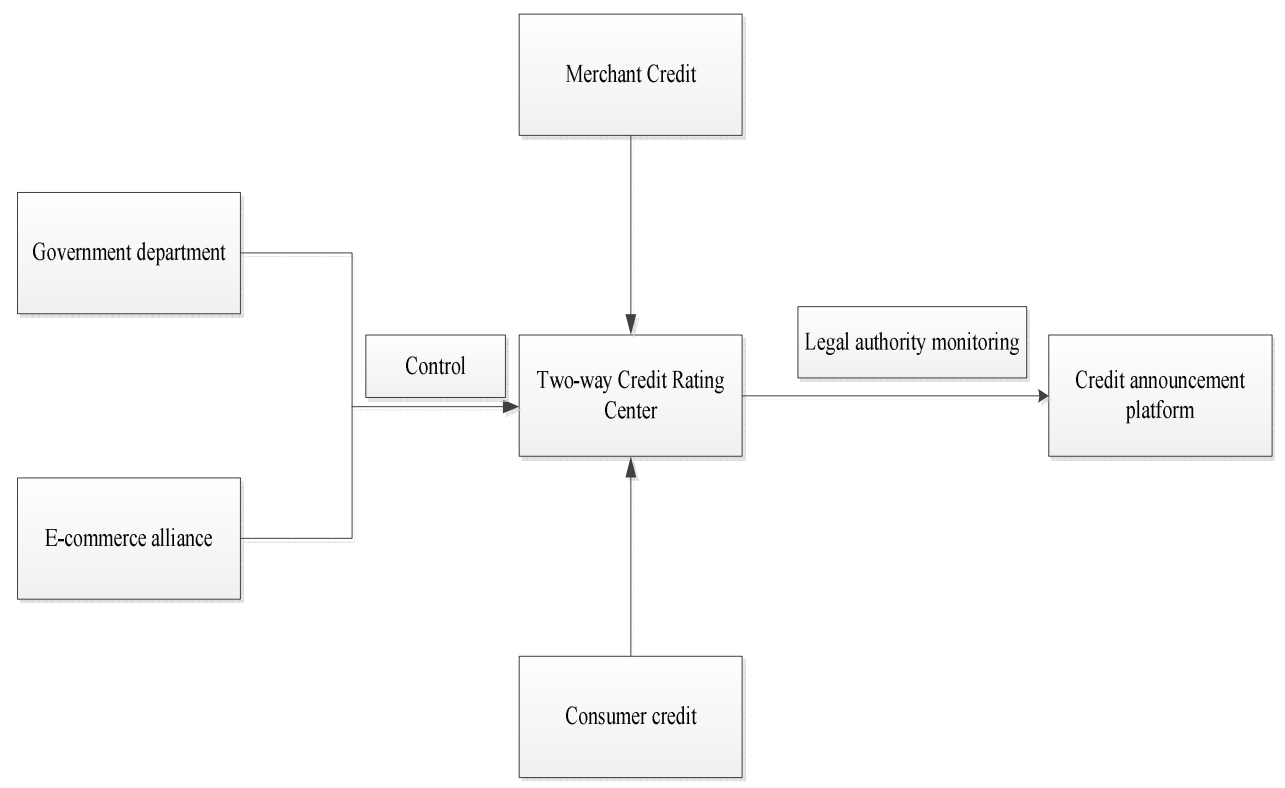

Figure 2: Operating model of the two-way e-commerce credit system

(1) The first step: Establish a two-way credit rating agency

With the credit evaluation center as the core, combined with the government departments and the e-commerce alliance to jointly implement credit evaluation work, 
Construction and Model Analysis of the Bidirectional E-Business Credit Evaluation System

this cooperation model can further promote the implementation of the two-way credit evaluation system. The e-commerce alliance is a non-profit organization composed of banks, payment gateways, e-commerce websites and other entities. It provides the most timely e-commerce transaction information and guarantees the rationality of the mechanism. Government departments are the authority to ensure the operation of the mechanism. The model in which an object that is directly related to the subject of the transaction serves as the monitor of the credit evaluation process can avoid artificial data modification, thereby reducing the impact of human interference on credit justice.

The establishment of a two-way credit rating agency is very important. In this paper, combined with the operating models of domestic and foreign credit investigation companies, the following three methods for the establishment of rating agencies are sorted out. They can provide references for the establishment of a two-way e-commerce credit rating center.

\section{Model 1: Establish a non-profit credit evaluation center led by the government}

This model mainly draws on the credit investigation system adopted by Germany, France and other European countries, that is, the "enterprise credit investigation system based on the central credit registration established by the central bank". The system is mainly funded by the government to establish a national database network system. The information processed by credit investigation is mainly for internal use by banks, serving commercial banks to prevent loan risks and central bank financial supervision and monetary policy decisions. The advantage of this model is that government intervention can strengthen the authority of credit results, compulsorily allow local entities to contribute data required for credit evaluation, and can concentrate various forces in a relatively short period of time to quickly establish a nationwide coverage. Credit investigation database within range. The disadvantage of this model is that when the government intervenes, it also has the disadvantage of interfering with the market. Since the government is not a direct participant in the market, the credit investigation system and implementation process established for non-profit purposes may not be able to accurately grasp the market. The pulse of change.

\section{Mode 2: Establish a commercial credit evaluation center with enterprises as the main body}

This model is mainly based on the market-oriented business operation model enterprise credit system represented by the American Credit Management Association (NACM), which is currently popular in the United States. Marketization and commercialization are the main business operations of consumer credit service 


\section{Qin-qin Fu and Pacheco Reyes Constantino Cristhian}

companies in the United States. They are neither controlled by the government, nor independent of commercial banks, and are a third party independent of financial institutions, government departments, and consumers. Its biggest advantage is that practitioners can build databases and provide services according to market needs. The competition mechanism promotes the expansion of this service range and continuous improvement of quality, which is very conducive to the localization of credit investigation products and services. The commercialized credit investigation system is based on the purpose of profitability and operates in a market-oriented manner. It has strong independence and neutrality. The commercialized operation is different from the credit investigation model of government organizations, and its commercial nature is to a certain extent. Helps enhance the quality of credit evaluation. The shortcomings of this model are: driven by interests, credit reporting organizations may violate the credit reporting principle due to excessive pursuit of revenue, concentrate their energy on shortterm gains, and ignore the needs of credit users; the professionalism of credit management practitioners The level is uneven, and the consistency, standardization and high quality of products and services cannot be guaranteed.

\section{Model 3: Establish a credit evaluation center composed of industry associations and enterprises}

This model is mainly based on the Japanese credit investigation system, that is, the "corporate credit investigation system composed of a membership credit investigation institution established by the bank association and a commercial credit investigation institution". For example, the Japan Banking Association has established a non-profit bank membership organization-the Japan Personal Credit Information Center, which is responsible for collecting credit from consumers or companies. The center has to pay when collecting information, and also when providing information services to maintain the development of the center, but it does not take profit as the fundamental purpose. The advantage of this model is that the cooperation between financial institutions and credit reporting agencies not only meets the needs of credit reporting for economic data (because of an important indicator of credit evaluation in economic data), but also ensures the authority and fairness of credit data (due to Is economic data provided by the bank). However, this model also has aspects that need to be improved. For example, since institutions that provide credit investigation services must have the characteristics of "neutrality" and "efficiency", credit companies must report credit information quickly, accurately and objectively, and therefore must have a good reputation. In the credit environment, the government should further improve relevant laws, regulations, and regulatory systems, issue publications on credit research, corporate credit status, credit 
Construction and Model Analysis of the Bidirectional E-Business Credit Evaluation System

education, etc., and establish online publications to promote society's attention and investment in credit.

(2) Step 2: Implement two-way credit assessment

First, the credit rating center obtains basic information about merchants and consumers from relevant entities involved in the e-commerce transaction process, including basic information about merchants, merchant credit records, customer reviews, transaction records, etc., as well as consumer-related Consumer funds, consumer integrity records, etc. Then, the evaluation center processes and analyzes the data with the help of credit evaluation methods (the analytic hierarchy process described below), and obtains a two-way credit evaluation result.

(3) Step 3: Announce the credit assessment results

In order to further ensure the openness, fairness and impartiality of the results, the two-way e-commerce credit evaluation results will be published on a specific information platform. The evaluation results will be visible to both the buyer, the seller and the parties in the e-commerce alliance. The platform is directly monitored by the national legal authority, Protect the legal rights of buyers and sellers, and prevent arbitrary tampering of credit results. The credit assessments published on the platform are divided into quarterly assessments and year-end assessments. Relevant databases are established, data results are retained, updated regularly, and query functions are provided to make information open and transparent to all participants.

\section{Implementation of the two-way e-commerce credit model-based on the analytic hierarchy process}

Assuming that a two-way credit evaluation center has been established, how does the institution carry out two-way credit evaluation? The implementation process is mainly divided into the following three key steps: First, select the credit evaluation indicator (system). Regarding the credit evaluation indicator system, scholars have developed a relatively mature scale, which can select a set of indicators or be based on a certain set of indicators. A set of indicators is partially revised. Secondly, to determine the weight of the evaluation index, there are many methods to determine the weight. The most commonly used method is tomography (Wang Juehui and Mao Haiyan, 2007), which is a combination of qualitative and quantitative, systematic and hierarchical In the analysis method, it divides the factors contained in the problem into three levels-the highest level, the middle level and the lowest level. In the process of determining the weights, it is necessary to set the comparative weights of the indicators of each level. Finally, collect 


\section{Qin-qin Fu and Pacheco Reyes Constantino Cristhian}

the original scores of each credit evaluation index, and combine the calculated index weight coefficients to calculate the final comprehensive credit score. Next, according to this process, the implementation of two-way credit evaluation is introduced based on simulated data.

Taking an e-commerce transaction as an example, the two-way e-commerce credit evaluation system is used to evaluate the credit of the target. First, the currently more recognized credit evaluation indicators are selected, namely, personal consumption characteristics, economic status, business ability, solvency, and profitability (Li Jingmiao et al., 2012; Jiang Minghui et al., 2004) as a credit indicator for both parties to the transaction; then use the analytic hierarchy process to set weights. This article takes ecommerce credit evaluation as the ultimate goal (the highest level), and considers consumer credit and merchant credit As the criterion layer (middle layer), take the factors that affect both parties to the transaction as the measure layer (lowest layer), establish a layered model as shown in Figure 3, and perform weight analysis based on this model. In the process of implementing the analytic hierarchy process (determining weight) The key step is to set the evaluation scale between factors. The usual weight setting standards are shown in Table 2. Finally, the original score and weight coefficient of each indicator are combined to obtain the final two-way credit score.

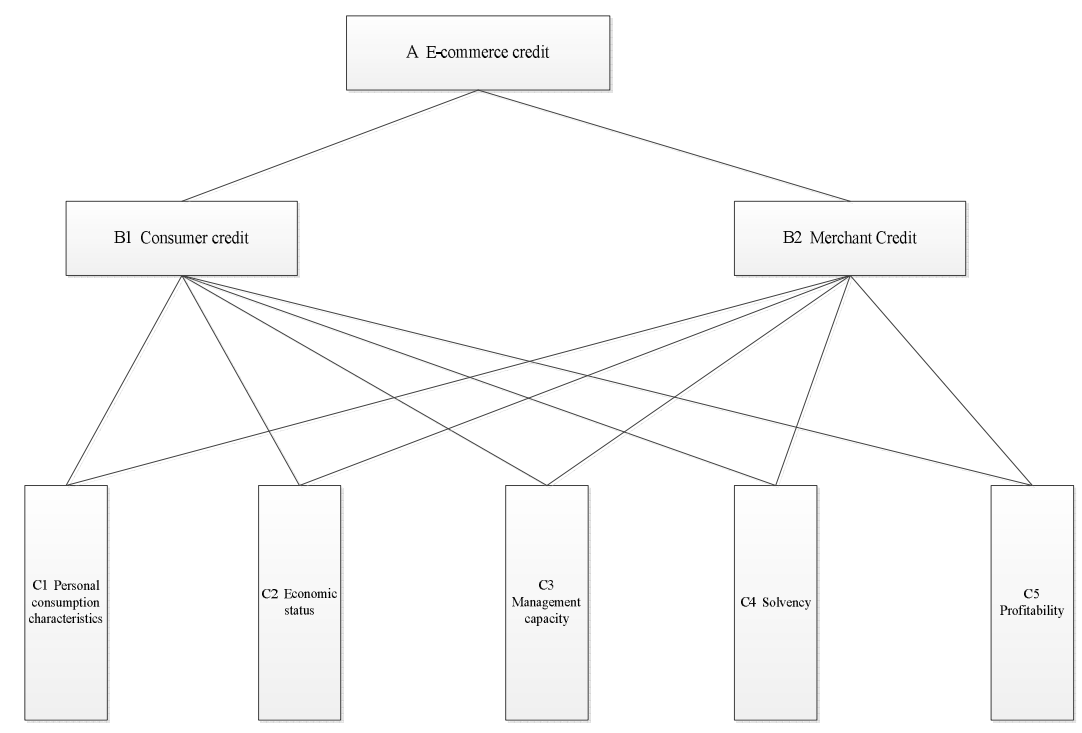

Figure 3: Two-way e-commerce credit hierarchy analysis model 
Construction and Model Analysis of the Bidirectional E-Business Credit Evaluation System

Table 2: Importance scale meaning table

\begin{tabular}{c|l}
\hline Importance scale & \multicolumn{1}{c}{ Meaning } \\
\hline 1 & $\begin{array}{l}\text { Indicates that two elements are of equal importance } \\
\text { Indicates that compared to two elements, the former } \\
\text { is slightly more important than the latter } \\
\text { Indicates that compared with two elements, the former } \\
\text { is obviously more important than the latter } \\
\text { Indicates that compared to two elements, the former is } \\
\text { more important than the latter } \\
7\end{array}$ \\
$\begin{array}{c}\text { Indicates that compared to two elements, the former is } \\
\text { extremely important than the latter } \\
\text { Indicates the intermediate value of the above judgment } \\
\text { If the ratio of the importance of element } \mathrm{i} \text { to } \\
\text { element } \mathrm{j} \text { is } a_{i j}, \\
\text { Then the ratio of element i to element } \mathrm{j} \text { importance } \\
\text { is } a_{i j}=1 / a_{j i}\end{array}$ \\
\hline
\end{tabular}

By comparing the degree of influence of different factors on the two subjects, the weight of the comparison between the first-level indicators is determined. We use the factors shown in Table 3 to compare the simulated data to calculate the weight coefficient. The meaning of each data in Table 3 can be explained based on Table 2. For example, personal consumption characteristics are more important than consumers' economic status, and their degree is between obviously important and slightly important, so the median value of judgment is 4; Personal consumption characteristics are important, and the degree of importance is between slightly important and equally important, so the median value of judgment is 2 ; personal economic status is more important than the merchant's solvency, and its degree is between strong and extremely important, so take the middle Value 8; merchant solvency is more important than merchant profitability, and its degree is between obviously important and strongly important, so the median value is 6; the importance scale of other indicators is similar to this, so I won't repeat it. The weight coefficient is calculated below. 
Qin-qin Fu and Pacheco Reyes Constantino Cristhian

Table 3: Comparison table of credit indicators

\begin{tabular}{cccccc}
\hline $\begin{array}{c}\text { Influencing } \\
\text { factors (C) }\end{array}$ & $\begin{array}{c}\text { Personal } \\
\text { consumption } \\
\text { characteristics }\end{array}$ & $\begin{array}{c}\text { economic } \\
\text { status }\end{array}$ & $\begin{array}{c}\text { Management } \\
\text { capacity }\end{array}$ & Solvency & Profitability \\
$\begin{array}{c}\text { Personal } \\
\text { consumption } \\
\text { characteristics } \\
\text { economic }\end{array}$ & 1 & 4 & $1 / 2$ & $1 / 4$ & $1 / 2$ \\
$\quad$ status & $1 / 4$ & 1 & $1 / 4$ & $1 / 8$ & $1 / 2$ \\
$\begin{array}{c}\text { Management } \\
\text { capacity }\end{array}$ & 2 & 4 & 1 & $1 / 2$ & 6 \\
Solvency & 4 & 8 & 2 & 1 & 6 \\
Profitability & 2 & 2 & $1 / 6$ & $1 / 6$ & 1 \\
\hline
\end{tabular}

First, determine the compatibility of the data matrix shown in Table 3. Calculate the geometric mean value of each row element in the judgment matrix and normalize it to obtain the main evaluation vector as

$W_{n}=\left(\begin{array}{lllll}0.1126 & 0.0470 & 0.2839 & 0.4556 & 0.1008\end{array}\right)$,

The matrix compatibility index is: $C I=0.0974, C R=0.0870<0.1$,

It conforms to the principle of consistency, so the above simulation data matrix is considered to be compatible, and the next step of weight analysis can be carried out.

Second, determine the weight. In the process of two-way e-commerce credit evaluation, since different indicators have different degrees of importance to merchant credit and consumer credit, it is necessary to further determine the indicator weight matrix according to Table 2, namely

$$
R=\left(\begin{array}{lllll}
0.1667 & 0.75 & 0.25 & 0.875 & 0.8 \\
0.8333 & 0.25 & 0.75 & 0.125 & 0.2
\end{array}\right)
$$

So the final evaluation matrix is $B=R \times W n$, According to the final evaluation matrix, the final combination weight can be obtained as $(0.6043$ 0.3956). This result shows that in the two-way e-commerce credit system based on the simulated data in this paper, the weight of consumer credit is 0.6043 , and the weight of merchants is 0.3956 .

Finally, calculate the final two-way credit score. If the merchant's initial credit score is a and the consumer's initial credit score is b, then combining the weight coefficient matrix,the final two-way credit evaluation result can be obtained as $c=0.3956 a+$ $0.6043 b$.In actual operation, users of credit information can judge the level of credit by comparing the value of the two-way credit evaluation results. At the same time, they can 
Construction and Model Analysis of the Bidirectional E-Business Credit Evaluation System

add or delete factors affecting credit according to actual problems, enhance credibility, and adjust model indicators appropriately.

Two-way e-commerce credit scoring results can provide effective reference information in many aspects. (1) Merchants can use the historical transaction data of consumers and other merchants to conduct credit analysis on consumption, determine the risk of transactions with them, and decide whether to transact with them, and vice versa, the same is true for consumers' reputation assessment of merchants. (2) Banks, credit cooperatives and other financial institutions can also use the results of the two-way ecommerce credit evaluation as a basis when evaluating lending risks to assess the creditworthiness of loan applicants engaged in e-commerce activities and determine whether to lend money to them. (3) For further promotion, it is also possible to use comprehensive panel data composed of the credit scores of a large number of ecommerce companies over a period of time (ie, comprehensive data of historical time series data and cross-sectional data of multiple companies) to enable regulatory authorities In addition, network operators can conduct a comprehensive analysis of the transaction credit between merchants and consumers in the e-commerce industry, thereby judging the growth and health of the e-commerce industry, capturing industry change information and implementing timely supervision to ensure the continuous and healthy development of the industry.

\section{Conclusion}

By analyzing the results of domestic and foreign credit research, this article finds that existing research focuses on the construction and application of one-way credit systems. Due to the one-sided and subjective nature of the evaluation subject, the evaluation results are often unfair. In order to improve the shortcomings of the traditional one-way credit system, this article first proposes a two-way e-commerce credit system, the essence of which is to establish a two-way credit rating center as the connection point, merchants and consumers as the credit evaluation objects, from banks, websites and other institutions A network structure credit evaluation system for obtaining credit information. Secondly, this article explains the operating mode of the two-way credit evaluation model, mainly based on selected credit evaluation indicators, through banks, third-party payment platforms and other transaction-related entities, while collecting credit data on merchants and consumers, using the hierarchical analysis model Determine the weight of credit evaluation indicators, and further calculate the final comprehensive credit score based on the scoring values of both parties. This result can provide a wide range of credit data for regulatory agencies, financial institutions, e-commerce websites and other entities, and monitor and trade the e-commerce industry. Provide direct information on 


\section{Qin-qin Fu and Pacheco Reyes Constantino Cristhian}

matters such as risk judgment and loan issuance evaluation to eliminate the unfairness under the traditional unilateral scoring mechanism, thereby improving the scientificity and rationality of credit evaluation.

\section{REFERENCES}

1. Wei Mingxia, Yu Jianhua and Sun Peng, Research on the evaluation mechanism of e-commerce credit establishment, Henan Social Sciences, 15 (6) (2007) 93-94.

2. D.Martin, Early warning of bank failure: A logit regression approach, Journal of Banking and Finance, 11 (1977) 249-276.

3. A.Giancarlo Marco and F.Varetto, Corporate distress diagnosis: Comparison using linear discriminate analysis and neural networks, Journal of Banking and Finance, 18 (1) (1994) 505-529.

4. D.Kimand L.Benbasat, Trust-related arguments in Internet stores: A framework for evaluation, Journal of Electroninc Commerce Research,4(2) (2003) 49-64.

5. Li Jingmiao, Wu Jiyi, Zhang Jianlin and Ke Limin, Credit evaluation of small and medium-sized enterprises in an e-commerce environment, System Engineering Theory and Practice, 32(3) (2012) 555-560

6. Ma Qingguo. The realistic road of China's development of e-commerce: analysis and confirmation, Management World, 2 (2004) 135-136.

7. Peng Hui and Wu Hong, The condition of honesty - The dependence of sellers' honesty product characteristics in $\mathrm{C} 2 \mathrm{C}$ e-commerce market, Management World, 4 (2011) 182-183.

8. Jiang Minghui, Wang Yalin, Zhao Xin and Huang Weiping, Application of k-nearest neighbor discriminant analysis method in personal credit evaluation, Quantitative Economics and Technical Economics Research, 2 (2004) 143-147.

9. Wang Juehui and Mao Haiyan, Research on the choice of e-commerce model based on analytic hierarchy process, Information Science, 25(4) (2007) 526-529.

10. Gao Junliang and Wang Jing, Integration of e-commerce credit model and establishment of credit system, Frontier, 5 (2006) 185-187.

11. E.I.Altman, Financial ratios discriminate analysis and the prediction of corporate bankruptcy, Journal of Finance, 23 (1968) 189-209.

12. Han Gang, Foreign risk measurement methods and suitability research International Finance Research, International Finance Research, 3 (2008) 43-47.

13. Fan Lifang, Comparative Research on Credit Evaluation Information Sources of Chinese and Foreign Enterprises, Library, Information and Knowledge, 11 (2007) 96-100.

14. Zhu Wen, Analyze the construction of the credit system of my country's ecommerce, Reform and Strategy, 6(25) (2009) 147-160. 